\title{
Accuracy of clinical diagnosis in primary degenerative dementia: correlation with neuropathological findings
}

\author{
RAIMO SULKAVA, MATTI HALTIA, * ANDERS PAETAU,* \\ JUHANI WIKSTRÖM, JORMA PALO \\ From the Departments of Neurology and Pathology, ${ }^{*}$ University of Helsinki, Helsinki, Finland
}

SUMMARY Neuropathological features and causes of death are presented in 27 deceased patients belonging to a prospective series of 71 hospitalised patients with primary degenerative dementia. The clinical criteria for primary degenerative dementia used in the present study were accurate enough to exclude patients with multi-infarct dementia. At necropsy, $82 \%$ of the cases had neuropathological changes of Alzheimer's disease. The clinical features of patients with other neuropathological changes are described. The most common immediate cause of death was bronchopneumonia which accounted for $59 \%$ of deaths in Alzheimer's disease.

Primary degenerative dementia is used as a clinical diagnosis for patients suspected of having a degenerative encephalopathy of unknown origin. ${ }^{1}$ It is often considered to be Alzheimer's disease or senile dementia of Alzheimer type if no other obvious cause is identified. ${ }^{2-9}$ This type of encephalopathy is present in over $50 \%$ of demented patients. ${ }^{10}$

In the present study the term Alzheimer's disease includes both presenile Alzheimer's disease and senile dementia of Alzheimer type since they compose a single clinical and neuropathological entity. ${ }^{11-14}$ Although the final diagnosis of Alzheimer's disease still requires neuropathological confirmation, either from a biopsy or necropsy specimen, correct diagnosis by non-invasive methods is becoming increasingly important. This goal can only be achieved by carefully correlating clinical data with neuropathological findings.

While the clinical criteria of primary degenerative dementia are widely used, follow-up studies with neuropathological examinations are rare $^{15}$ and often retrospective. ${ }^{16}{ }^{17}$ We now present data on 27 deceased patients of a prospective series of 71 patients with primary degenerative dementia, examining the accuracy of clinical diagnosis especially in relation to Alzheimer's disease. We also

Address for reprint requests: Dr $R$ Sulkava, Department of Neurology, University of Helsinki, Haartmaninkatu 4, SF-00290 Helsinki 29, Finland.

Received 2 August 1982

Accepted 4 October 1982 present the immediate and underlying causes of death for these patients.

\section{Patients and Methods}

The series of 71 consecutive patients with primary degenerative dementia included 36 presenile cases (onset of symptoms before the age of 65 years) and 35 senile cases (onset of symptoms after the age of 65). All were in-patients at the Koskela Geriatric Hospital in Helsinki and entered the study between June 1978 and June 1980 . The criteria for selection of the patients were designed to exclude aetiological factors other than primary degenerative dementia and were essentially those of Roth ${ }^{18}$ with some modifications (table 1). No attempt was made to differentiate Alzheimer's disease from other primary degenerative dementias, for example Pick's disease, during life.

Patient histories were collected from family members and hospital records. Neurological examination of all patients was carried out by one of us (RS). A modified Luria's neuropsychological test battery ${ }^{19}$ was presented to all those patients who could at least partly understand the instructions. The tests were carried out from 3 weeks to 12 months prior to the patient's death except in one case 30 months before the death. An electroencephalogram (EEG) was recorded from each patient once or twice a year. Two qualities of EEG abnormality, generalised or diffuse slowing and paroxysmal abnormality, were graded 0 (lack of any abnormality) to 6 (most severe abnormality). The total EEG score was obtained by multiplying the score for generalised or diffuse slowing by two and adding the product to the score for paroxysmal activity. ${ }^{14}$ The maximum score was thus 18 . A chest radiograph and an electrocardiogram were taken in all cases, and brain CT scan or pneumoencephalogram was obtained in 12 presenile cases. The laboratory tests included blood cell count, blood 
Table 1 Clinical criteria for primary degenerative dementia

1. Extensive progressive failure of intellectual capacity during adult life

2. Deterioration of memory as the first symptom followed by disorientation, a failure in the common activities of everyday life, and flattening of personality. Psychiatric symptoms such as paranoic and depressive features possible

3. Special neuropsychological symptoms such as apraxia, agnosia, aphasia, and lowered alertness

4. No signs of focal brain damage in clinical neurological examination to refer to other aetiology, for example, vascular lesions, tumours, brain injuries

5. In other investigations (blood tests, cerebrospinal fluid tests, electroencephalogram, neuroradiological examinations) nothing to indicate a special aetiology for the condition

6. Depression and psychoses excluded by clinical history, neuropsychological examination, drug treatment and hospital observation

7. In the clinical history nothing to indicate other aetiological factors, for example alcoholism, drug abuse, sequelae of brain injuries, Parkinsonism

sedimentation rate, serum creatinine, plasma glucose, total cholesterol, triglycerides, sodium, potassium, chloride, calcium, phosphate, vitamin $B_{12}$, folic acid, transaminases, alkaline phosphatase, urate, serum iron, transferrin iron binding capacity, electrophoresis of serum proteins, serological test for syphilis (Sitolipin), and thyroid function tests. Tests for cerebrospinal fluid (CSF) included cell counts, glucose and total protein determinations, as well as protein electrophoresis. Immunoelectrophoresis of CSF proteins was done in 27 cases.

All the 27 deceased patients were necropsied and a neuropathological examination was carried out. From each patient the left half of the brain was fixed in $4 \%$ phosphate
Table 2 Neuropathological diagnoses in 27 autopsied patients fulfilling the criteria for primary degenerative dementia

\begin{tabular}{lc}
\hline Diagnosis & $N(\%)$ \\
\hline Alzheimer's disease & $22(82)$ \\
Other conditions: & $5(18)$ \\
Parkinson's disease & 1 \\
Hippocampal neuronal loss and gliosis & 2 \\
$\quad$ and subcortical gliosis & 2 \\
Non-specific encephalopathy & 2 \\
\hline
\end{tabular}

buffered formaldehyde and specimens were taken from the following regions: temporal lobe including the hippocampus, frontal lobe, occiptal lobe including area striata, basal ganglia, thalamus, substantia nigra, pons, medulla oblongata and cerebellum. Paraffin sections, $10 \mu \mathrm{m}$ thick, were stained with haematoxylin eosin, Luxol fast blue/ cresyl violet, Holmes' silver stain, periodic acid/Schiff, and Congo red. Neuropathological criteria for Alzheimer's disease required abundant neurofibrillary tangles and senile plaques in the hippocampus plus moderate to large numbers of tangles and plaques in the neocortex. ${ }^{21} 22 \chi^{2}$ test and Student's $t$ test were used for statistical analysis.

\section{Results}

All the brains had marked degenerative changes but no major vascular lesions. Twenty-two $(82 \%)$ had neuropathological changes typical of Alzheimer's disease while five $(18 \%)$ had a degenerative encephalopathy of some other type (table 2). There

Table 3 Clinical characteristics of the necropsied patients with Alzheimer's disease and other conditions

\begin{tabular}{lllll}
\hline Diagnosis & $\begin{array}{l}\text { Sex } \\
(M / F)\end{array}$ & $\begin{array}{l}\text { Age at death } \\
(\text { mean } \pm S D)\end{array}$ & $\begin{array}{l}\text { EEG score } \\
(\text { mean } \pm S D)\end{array}$ & $\begin{array}{l}\text { Positive family } \\
\text { history }\end{array}$ \\
\hline Alzheimer's disease & $9 / 13$ & $71.4 \pm 6.4 \mathrm{yrs}$ & $9.5 \pm 3.4$ & $4(18 \%)$ \\
Other & $1 / 4$ & $71.8 \pm 9.9 \mathrm{yrs}$ & $6.0 \pm 2.5^{*}$ & $4(80 \%) \dagger$ \\
\hline
\end{tabular}

p $<0.02,+p<0.05$

Table 4 Clinical and neuropathological findings in five necropsied patients without changes typical of Alzheimer's disease

\begin{tabular}{|c|c|c|c|c|}
\hline $\begin{array}{l}\text { Patient } \\
\text { No }\end{array}$ & $\operatorname{Sex}$ & $\begin{array}{l}\text { Age at death/ } \\
\text { duration of } \\
\text { symptoms (yr) }\end{array}$ & Neuropathology & Selected clinical features \\
\hline 1 & $\mathbf{M}$ & $71 / 6$ & $\begin{array}{l}\text { Neuronal loss and gliosis in the hippocampus } \\
\text { and diffuse subcortical gliosis }\end{array}$ & $\begin{array}{l}\text { Brother and sister demented } \\
\text { No aphasia, extrapyramidal signs or primitive } \\
\text { reflexes }\end{array}$ \\
\hline 2 & $\mathbf{F}$ & $89 / 3$ & $\begin{array}{l}\text { Neuronal loss and gliosis in the hippocampus } \\
\text { and perivascular gliotic foci in the basal ganglia } \\
\text { and subcortical gliosis }\end{array}$ & $\begin{array}{l}\text { Only moderate degree of dementia } \\
\text { No aphasia, no extrapyramidal signs }\end{array}$ \\
\hline 3 & $\mathbf{F}$ & $67 / 4$ & Nigral neuronal loss and Lewy bodies & $\begin{array}{l}\text { Sister demented; brother had extrapyramidal signs } \\
\text { No primitive refexes } \\
\text { Only slight slowing in EEG }\end{array}$ \\
\hline 4 & $\mathbf{F}$ & $67 / 5$ & $\begin{array}{l}\text { Non-specific changes (frontally accentuated gyral } \\
\text { atrophy, slight numbers of tangles in the } \\
\text { hippocampus and in the frontal and temporal } \\
\text { neocortex, occasional plaques) }\end{array}$ & $\begin{array}{l}\text { Sister demented } \\
\text { Episodes of confusion } 5 \text { yrs before the onset of } \\
\text { dementia probably due to hyperthyroidism } \\
\text { Mature onset diabetes }\end{array}$ \\
\hline 5 & $\mathbf{F}$ & $65 / 5$ & $\begin{array}{l}\text { Non-specific changes (neuronal loss in the } \\
\text { cortex, abundant lipofuscin in neurons) }\end{array}$ & $\begin{array}{l}\text { Brother and sister demented } \\
\text { Attacks of headache and vomiting } \\
\text { Positive Babinski sign } \\
\text { Myoclonus in the lower extremities } \\
\text { Early faecal incontinence }\end{array}$ \\
\hline
\end{tabular}


Table 5 The immediate and underlying causes of death in 27 patients with primary degenerative dementia

\begin{tabular}{lr}
\hline Alzheimer's disease (22) & $\mathrm{N}(\%)$ \\
\hline Immediate cause & $13(59)$ \\
$\quad$ Bronchopneumonia & $4(18)$ \\
Pulmonary embolism & $2(9)$ \\
Deep venous and caval thrombosis & $3(14)$ \\
$\quad$ No obvious immediate cause & \\
Underlying cause & $18(81)$ \\
$\quad$ Alzheimer's disease only & $2(9)$ \\
Adenocarcinoma of pancreas + Alzheimer's disease & $1(5)$ \\
Adenocarcinoma of stomach + Alzheimer's disease & 1 Disseminated tuberculosis of lungs \\
$\quad$ and liver + Alzheimers disease & $1(5)$ \\
Other conditions & \\
Immediate cause & \\
$\quad$ Bronchopneumonia & $4(80)$ \\
Pulmonary embolism & $1(20)$ \\
\hline
\end{tabular}

were more women than men in both the Alzheimer's disease and non-Alzheimer's disease groups and the mean age at death was the same, 71 years (table 3 ). The mean score for EEG abnormalities was significantly higher and the frequency of first-degree relatives similarly affected significantly lower in the Alzheimer's disease group. Duration of the symptoms was $5.9 \pm 2.6$ years (mean $\pm \mathrm{SD}$ ) for Alzheimer's disease patients and $4 \cdot 6 \pm 1 \cdot 1$ years for the other patients, a non-significant difference. Clinical data on all the 71 patients of the series have been published elsewhere. ${ }^{14} 20$ The clinical and neuropathological findings of the five nonAlzheimer's disease patients are presented in table 4.

The immediate and underlying causes of death of the 27 deceased patients are shown in table 5. The most common immediate cause in the Alzheimer's disease group was bronchopneumonia which was observed in 13 cases $(59 \%)$. No obvious immediate cause was found in three patients $(14 \%)$. Other diseases that could be regarded as underlying causes of death were found in four Alzheimer's disease patients - these were three cases of cancer and one case of tuberculosis-but in $81 \%$ Alzheimer's disease appeared to be the only underlying disease. Bronchopneumonia was also the major immediate cause of death in the non-Alzheimer's disease group where no other underlying causes were diagnosed in addition to the encephalopathies listed in table 4.

\section{Discussion}

According to Roth $^{18}{ }^{23}$ senile dementia (senile psychosis) is a condition with a history of gradual and continually progressive failure in the common activities of everyday life. The clinical picture is dominated by a failure of memory and intellect and disorganisation of personality, not attributable to specific causes such as infection, neoplasm, chronic intoxication or cerebrovascular disease known to have produced cerebral infarction. These criteria were not originally based on neuropathological studies but they were successfully used by us to select patients with primary degenerative dementia since all the patients fulfilling the clinical criteria were found to have neuropathological changes of degenerative encephalopathy at necropsy. The case of Parkinson's disease is thus also included although dementia is not a consistent feature in that disease. ${ }^{24}$

Eighty-two per cent of the deceased, clinically diagosed primary degenerative dementia patients had Alzheimer's disease, a figure higher than in some earlier studies where it has varied from $43 \%$ to $77 \%{ }^{15-17}$ and where the majority of the other patients were found to have vascular lesions. Because no cases of multi-infarct dementia were found in the present series the clinical criteria seemed to be able to differentiate primary degenerative dementia reliably from multi-infarct dementia, at least in a series of inpatients with moderate to severe dementia. On the other hand, this differentiation may be more difficult in early cases with mild, non-specific symptoms and signs. In fact, of mildly demented patients $57 \%$ to $68 \%$ show no signs of further deterioration. ${ }^{16} 25$ Vascular cases are not expected to accumulate among the living demented patients of the series since the duration of multi-infarct dementia is shorter than that of primary degenerative dementia. ${ }^{26}$ While Hachinski's Ischemic Score is known to differentiate patients with multi-infarct dementia from those with degenerative dementia ${ }^{21}{ }^{27}$ the same result can be achieved by starting from the criteria for primary degenerative dementia, as shown in our study.

One-fifth of the patients with Alzheimer's disease were familial, a finding in accordance with earlier observations. ${ }^{28}$ In contrast, four out of five nonAlzheimer's disease patients had similarly affected sibs. It is well-known that familial cases are found in almost all dementing illnesses including, for example, Creutzfeldt-Jakob disease, ${ }^{29}$ so-called progressive subcortical gliosis, ${ }^{30}$ Parkinson's disease,${ }^{31}$ and multi-infarct dementia. ${ }^{32}$ There are also cases of familial dementia with non-specific neuropathological findings. ${ }^{33}$

Neuropathological changes of Parkinson's disease, (neuronal loss of substantia nigra and Lewy bodies) were found in one of our patients. She presented with progressive dementia and developed extrapyramidal signs only in the final stage of her illness. The prevalence of dementia in Parkinson's disease varies between $29 \%$ and $56 \% .{ }^{24}{ }^{34}{ }^{35}$ It is usually regarded as a symptom of advanced Parkinsonism but it is known to antedate Parkinson's disease in $11 \%$ of patients. ${ }^{35}$ It may be difficult to separate advanced cases of Alzheimer's disease with dementia, hypokinesia and 
rigidity from those of Parkinson's disease with the same features although the history of the early disturbance of memory, the lack of tremor, and the presence of paratonia often indicates the diagnosis of Alzheimer's disease..$^{14}$

In an earlier series ${ }^{36}$ all the Parkinsonian patients with severe dementia had changes of Alzheimer's disease in the brain besides those of Parkinson's disease. Our case with severe dementia did not belong to that mixed group but was neuropathologically an example of pure Parkinson's disease. On the other hand, no patient with Alzheimer's disease had neuropathological changes of Parkinson's disease Thus our results do not support the view that Alzheimer's disease and Parkinson's disease are two aspects of the same disorder. ${ }^{34} 36$

Two of our non-Alzheimer's disease patients had common neuropathological features, severe neuronal loss and gliosis in the hippocampus and subcortical gliosis. These cases bore some resemblance to so-called progressive subcortical gliosis. ${ }^{30}{ }^{37}$

No diagnostic changes were found in the brains of two patients. They may have had a condition that has been called "simple senile dementia", that is the clinical picture of Alzheimer's disease without its histological changes. ${ }^{158}$ It has been suggested that this condition is an early evolutionary form of Alzheimer's disease in which cortical tangles and plaques develop later in the course of the disease. ${ }^{18}$ The duration of the disease in both of these cases, five years, should have been long enough to permit the appearance of Alzheimer changes in the brain, especially when the changes were abundant in many Alzheimer's disease cases of shorter duration. It is therefore more likely that the cases represent other entities or variants of Alzheimer's disease not yet recognised.

It is estimated that Alzheimer's disease is the fourth or fifth most common cause of death in the USA although it is not registered in the vital statistics tables. ${ }^{39}$ Non-specific immediate causes, such as pneumonia, account for $90 \%$ of deaths in senile dementia. ${ }^{2}$ Pneumonia was the most common immediate cause also in our series. However, no obvious immediate cause of death was found in $14 \%$ of Alzheimer's disease patients suggesting a failure in the central regulation of vital functions, such as respiration. In $81 \%$ Alzheimer's disease was the only underlying primary cause of death but there were three cases of malignant diseases and one case of tuberculosis in addition to Alzheimer's disease. Since Alzheimer's disease is also a "malignant" disease which drastically diminishes the patient's life expectancy ${ }^{39}$ it should always be mentioned in the death certificates of these patients.
This investigation was supported by grants from the Yrjö Jahnsson Foundation.

\section{References}

${ }^{1}$ American Psychiatric Association. Diagnostic and statistical manual of mental disorders, 3rd Ed. Washington, DC: APA, 1980.

${ }^{2}$ Kay DWK. Outcome and cause of death in mental disorders of old age: a long-term follow-up of functional and organic psychoses. Acta Psychiatr Scand 1962;38:249-76.

${ }^{3}$ Nielsen J. Geronto-psychiatric period-prevalence investigation in a geographically delimited population. Acta Psychiatr Scand 1962;38:307-30.

${ }^{4}$ Rosenstock HA. Alzheimer's presenile dementia. A review of 11 clinically diagnosed cases. Dis Nerv Syst 1970;31:826-9.

${ }^{5}$ Fox JH, Topel JL, Huckman MS. Dementia in the elderly-a search for treatable illnesses. J Gerontol 1975;30:557-64.

${ }^{6}$ Stefoski D, Bergen D, Fox J, Morrell F, Huckman M, Ramsey R. Correlation between diffuse EEG abnormalities and cerebral atrophy in senile dementia. $J$ Neurol Neurosurg Psychiatry 1976;39:751-5.

${ }^{7}$ Jacoby RJ, Levy R. Computed tomography in the elderly. 2. Senile dementia: diagnosis and functional impairment. Br J Psychiatry 1980;136:256-69.

${ }^{8}$ Merskey H, Ball MJ, Blume WT et al. Relationship between psychological measurements and cerebral organic changes in Alzheimer's disease. Can J Neurol Sci 1980;7:45-9.

${ }^{9}$ Brinkman SD, Sarwar M, Levin HS, Morris HH. Quantitative indexes of computed tomography in dementia and normal aging. Radiology 1981;138:8992.

${ }^{10}$ Wells C. Role of stroke in dementia. Stroke 1978;9:1-3.

${ }^{11}$ Hooper MW, Vogel FS. The limbic system in Alzheimer's disease. Am J Pathol 1976;85:1-13.

${ }^{12}$ Neumann MA, Cohn R. Epidemiological approach to questions of identity of Alzheimer's and senile brain disease: a proposal. In: Katzman R, Terry RD, Bick $\mathrm{KL}$, eds. Alzheimer's disease: senile dementia and related disorders. New York: Raven Press 1978:27-34.

${ }^{13}$ Bowen DM, Spillane JA, Curzon G, Meier-Ruge W, White $\mathbf{P}$, Goodhardt $\mathbf{M}$, Iwangoff $\mathbf{P}$, Davison AN. Accelerated ageing or selective neuronal loss as an important cause of dementia. Lancet 1979;1:11-4.

${ }^{14}$ Sulkava R. Alzheimer's disease and senile dementia of Alzheimer type. A comparative study. Acta Neurol Scand 1982;65:636-50.

${ }^{15}$ Constantinidis J. Is Alzheimer's disease a major form of senile dementia? Clinical, anatomical, and genetic data. In: Katzman R, Terry RD, Bick KL, eds. Alzheimer's disease: senile dementia and related disorders. New York: Raven Press 1978:15-25.

${ }^{16}$ Nott PN, Fleminger JJ. Presenile dementia: the difficulties of early diagnosis. Acta Psychiatr Scand 1975;51:210-7.

${ }^{17}$ Müller HF, Schwartz G. Electroencephalograms and autopsy findings in geropsychiatry. J Gerontol 1978;33:504-13. 
${ }^{18}$ Roth M. The natural history of mental disorder in old age. J Ment Sci 1955;101:281-301.

${ }^{19}$ Christensen A-L. Luria's neuropsychological investigation. Copenhagen: Munksgaard 1975.

${ }^{20}$ Sulkava R, Amberla K. Alzheimer's disease and senile dementia of Alzheimer type. A neuropsychological study. Acta Neurol Scand 1982;65:651-60.

${ }^{21}$ Rosen WG, Terry RD, Fuld PA, Katzman R, Peck A. Pathological verification of ischemic score in differentation of dementias. Ann Neurol 1980;7:486-8.

${ }^{22}$ Tomlinson BE, Irving D, Blessed G. Cell loss in the locus coeruleus in senile dementia of Alzheimer type. $J$ Neurol Sci 1981;49:419-28.

${ }^{23}$ Roth M, Myers DH. The diagnosis of dementia. Br J Psychiatry 1975;spec publ 9:87-99.

${ }^{24}$ Marttila R, Rinne U. Dementia in Parkinson's disease. Acta Neurol Scand 1976;54:431-41.

${ }^{25}$ Bergmann $\mathrm{K}$. The problem of early diagnosis. In: Glen AIM, Whalley LJ, eds. Alzheimer's disease. Early recognition of potentially reversible deficits. Edinburgh: Churchill Livingstone 1979:68-77.

${ }^{26}$ Wang HS. Prognosis in dementia and related disorders in the aged. In: Katzman R, Terry RD, Bick KL, eds. $A^{\prime}$ zheimer's disease: senile dementia and related disorders. New York: Raven Press 1978:309-13.

${ }^{27}$ Hachinski VC, Iliff LD, Zihlka E. et al. Cerebral blood flow in dementia. Arch Neurol 1975;32:632-7.

${ }^{28}$ Lauter H. Zur Klinik und Psychopathologie der Alzheimerschen Krankheit. Psychiatria Clin 1968;1:85-108.

${ }^{29}$ Haltia M, Kovanen J, van Creval H, Bots GThAM, Stefanko S. Familial Creutzfeldt-Jakob disease. J Neurol Sci 1979;42:381-9.
${ }^{30}$ Neumann MA, Cohn R. Progressive subcortical gliosis, a rare form of presenile dementia. Brain 1967;90:40517.

${ }^{31}$ Marttila R. Epidemiological, clinical, and virusserological studies of Parkinson's disease. Reports from the Department of Neurology, University of Turku, No 6, Turku 1974.

${ }^{32}$ Sourander $\mathrm{P}$, Wålinder J. Hereditary multi-infarct dementia. Morphological and clinical studies of a new disease. Acta Neuropath 1977;39:247-54.

${ }^{33}$ Kim RC, Collins GH, Parisi JE, Wright AW, Chu YB. Familial dementia of adult onset with pathological findings of a "non-specific" nature. Brain 1981;104:6178.

${ }^{34}$ Hakim AM, Mathieson G. Dementia in Parkinson disease: a neuropathologic study. Neurology (Minneap) 1979;29:1209-14.

${ }^{35}$ Lieberman A, Dziatolowski M, Kupersmith M, Serby $\dot{\mathbf{M}}$, Goodgold A, Korein J, Goldstein M. Dementia in Parkinson disease. Ann Neurol 1979;6:355-9.

${ }^{36}$ Boller F, Mizutani T, Roessmann U, Gambetti P. Parkinson disease, dementia, and Alzheimer disease: clinicopathological correlations. Ann Neurol 1980;7:329-35.

${ }^{37}$ Neumann MA. Pick's disease. J Neuropathol Exp Neurol 1949;8:255-82.

${ }^{38}$ Sjögren H. Clinical analysis of Morbus Alzheimer and Morbus Pick. Acta Psychiatr Neurol Scand 1952;suppl 82:67-115.

${ }^{39}$ Katzman $R$. The prevalence and malignancy of Alzheimer disease. Arch Neurol 1976;33:217-8. 